\title{
María CASTAÑEDA DE LA PAZ y Michel R. OUDIJK, El Códice Mexicanus
}

\author{
Miguel Ángel Ruz Barrio
}

\section{OpenEdition}

Journals

\section{Edición electrónica}

URL: https://journals.openedition.org/jsa/19680

DOI: 10.4000/jsa. 19680

ISSN: 1957-7842

\section{Editor}

Société des américanistes

\section{Edición impresa}

Fecha de publicación: 30 septiembre 2021

Paginación: 231-235

ISSN: 0037-9174

\section{Referencia electrónica}

Miguel Ángel Ruz Barrio, «María castañeda de LA PAz y Michel R. oudiJk, El Códice Mexicanus», Journal de la Société des américanistes [En línea], 107-1 | 2021, Publicado el 30 septiembre 2021, consultado el 04 septiembre 2022. URL: http://journals.openedition.org/jsa/19680 ; DOl: https://doi.org/10.4000/jsa. 19680

Este documento fue generado automáticamente el 4 septiembre 2022.

All rights reserved 


\title{
María CASTAÑEDA DE LA PAZ y Michel R. oudijK, El Códice Mexicanus
}

\author{
Miguel Ángel Ruz Barrio
}

\section{REFERENCIA}

María CASTAÑEDA DE LA PAZ y Michel R. OUDIJK, El Códice Mexicanus, Universidad Nacional Autónoma de México, Coordinación de Humanidades, Instituto de Investigaciones Antropológicas, Instituto de Investigaciones Históricas, Instituto de Investigaciones Filológicas/El Colegio Mexiquense/Fundación Alfredo Harp Helú Oaxaca, México, 2019, 362 p., 2 t., bibliogr., index, append., ill. (en negro y en color), fotos (en color), mapas, tabl.

1 Este libro pone al alcance de los investigadores, estudiantes y otras personas interesadas un códice mesoamericano reproducido en alta calidad con fotografías a color. Si bien en la actualidad se puede acceder a algunos de estos documentos en formato digital, continúa siendo necesaria la impresión de ediciones como la que se presenta aquí del Códice Mexicanus conservado en la Bibliothèque nationale de France (BNF), en la sección de Manuscritos Mexicanos (23-24) porque no se trata solo de dar acceso a una reproducción, sino que se acompaña de un profundo estudio que permite entender y conocer el códice'. Ambas partes de la obra serían incompresibles de manera independiente, sobre todo para aquellos que no tienen un conocimiento profundo del tema. Asimismo, el comentario del códice ha sido elaborado, además, sobre una extensa revisión de otras fuentes y se apoya en una serie de figuras y tablas que contribuyen a mejorar la comprensión del manuscrito. Todo ello finalmente nos ofrece una obra muy completa y novedosa.

2 Su publicación ha coincidido prácticamente con el estudio coetáneo de Lori Boornazian Diel (2018) sobre el mismo códice, publicado en inglés por la University of Texas Press. Ambos trabajos se desarrollaron de manera paralela, como reconocen los autores en la introducción del libro que aquí presentamos. Entre ambos libros existen diferencias que 
no trataremos aquí por motivos de espacio, pero la presencia de estas dos publicaciones nos demuestra el interés que ha suscitado recientemente este manuscrito.

El Códice Mexicanus, compuesto por 51 hojas de pequeño tamaño $(10 \times 20 \mathrm{~cm})$, solo había recibido el interés previo de Ernest Mengin (1952), quien publicó un comentario muy general sobre este con varias fotografías, y posteriormente de breves menciones por parte de algunos interesados como Joaquín Galarza, Hans Prem o Susan Spitler. Sin embargo, ninguno de ellos llegó a entrar en un análisis profundo de su rico contenido, que combina aspectos de historia y religión prehispánica compuestos desde el punto de vista indígena de la segunda mitad del siglo xVI, es decir, dentro de un mundo colonial ya asentado. En años recientes, los autores del libro que presentamos, junto a Diel, han escrito algunos artículos con avances relativos a su estudio que han culminado en las dos obras recién publicadas.

La edición que comentamos ha estado a cargo de varias instituciones mexicanas que han aunado esfuerzos para ofrecer al público interesado este interesante trabajo. Cabe destacar que tienen una experiencia previa en la publicación de facsímiles con estudio de códices mesoamericanos, lo que explica que hayan decidido colaborar para este proyecto y el resultado obtenido. Además, hay que destacar la larga trayectoria que tienen los autores del estudio, María Castañeda de la Paz y Michel R. Oudijk, en la investigación sobre los códices mesoamericanos y la historia indígena mexicana en general.

La obra consta de dos tomos en los que se presenta el comentario (tomo I) y la reproducción fotográfica a color del Códice Mexicanus (tomo II). El primero de ellos se estructura en seis capítulos, junto a la introducción, las conclusiones, apéndices, bibliografía y varios índices (figuras y cuadros). Cada uno de los capítulos se refiere a alguno de los elementos del contenido del códice, como veremos más adelante. Si bien algunos capítulos están escritos de manera individual, se percibe la visión de conjunto y la buena articulación entre todas sus partes. De este modo, tras su lectura queda una visión muy completa del Códice Mexicanus, que permite además un acercamiento a esta fuente para futuros estudios. El aparato crítico del estudio es amplio, demostrando el conocimiento fruto de la extensa experiencia de los autores en la investigación sobre este y otros asuntos similares.

El tomo II, como hemos señalado, contiene la reproducción fotográfica a color de las 102 láminas que componen el Códice Mexicanus. La calidad tanto de la impresión como del papel logran un resultado óptimo para el objetivo buscado en este tipo de ediciones. Así, resulta de gran utilidad su presentación de manera independiente al estudio para poder seguirlo a la par que se lee la explicación del contenido.

Oudijk sobre el Códice Mexicanus, como se ha indicado, se encuentra en el tomo I y se organiza en seis capítulos, a los que se añaden introducción, conclusiones y apéndices.

El primero de los capítulos, "El almanaque médico", escrito por Michel R. Oudijk, se centra en explicar la sección inicial del Códice Mexicanus (láminas 1-15) junto al tonalpohualli situado al final (láminas 89-102). Estas páginas nos ilustran, en palabras del autor, sobre el "interés de algunos intelectuales nahuas del siglo xvi por entender el calendario europeo y su complejidad interna" (p. 23). Este capítulo muestra la riqueza del nuevo entorno cultural que se construyó en el mundo novohispano dentro del cual los miembros de una élite indígena, desde su punto de vista, trataron de asimilar los saberes procedentes del mundo europeo y combinarlos con los mesoamericanos. Tras ello, había 
un interés que podemos calificar como práctico de diversos aspectos como el relativo a la concepción de la medicina en la época, ya que, por ejemplo, se recogió una tabla de humores y otra de sangrados, junto a un hombre de zodiaco. Oudijk muestra cómo los autores de este códice trataron de combinar estos elementos europeos con un tonalamatl. Asimismo, otro de los aspectos interesantes que comenta Oudijk es cómo uno de los autores que intervino en el Mexicanus trató de ajustar el calendario cristiano con el nahua. Este intento coincidió con la llegada a la Nueva España del cambio al calendario gregoriano, lo que supuso para el autor una modificación en sus cuentas, aunque finalmente acabó abandonando esta tarea por la complejidad que suponía. Este hecho, además, constituye uno de los elementos que han contribuido en la datación del Códice Mexicanus propuesta por los autores del comentario.

El segundo capítulo, escrito por Castañeda de la Paz, se ocupa de la genealogía de la casa real de Tenochtitlan (láminas 16-17). En él la autora muestra su amplio manejo sobre la historia prehispánica de los mexica-tenochca y recoge varios de sus hallazgos en investigaciones previas (véase, por ejemplo, Castañeda de la Paz 2013) para comentar la sección. Entre otras cosas, su análisis de esta lámina le lleva a concluir que su representación muestra los lazos de este códice, y en concreto de la genealogía (o su fuente original), con el tecpan de San Sebastián Atzacualco al que se vinculaban los descendientes de Axayacatl y, en concreto, los Alvarado y Moctezuma. Además, se refiere brevemente al nexo que tiene esta lámina con los códices Techialoyan y, en concreto, con el Códice García Granados a través de la figura de don Diego García (Castañeda de la Paz 2017).

10 El tercer y cuarto capítulo continúan con el contenido histórico: prehispánico (láminas 18-76) y colonial (láminas 76-87), según la división que se establece en la obra a fines prácticos para el análisis de los anales históricos que componen la mayor parte del Códice Mexicanus. El capítulo tercero es de autoría individual de Castañeda de la Paz, que realiza un detallado comentario de todas las láminas relativas a la época prehispánica, desde el inicio de la peregrinación hasta la conquista española, apoyándose en su conocimiento de la historia mexica-tenochca y sus fuentes. Si bien confronta cada uno de los hechos recogidos en los anales con diversas fuentes, el comentario de cada uno se ha limitado, por motivos de espacio, a mostrar los elementos fundamentales para la explicación del contenido del manuscrito. Sin embargo, constituye una rica aportación que se puede completar con otros estudios relativos a este asunto, como los de la propia Castañeda de la Paz. Entre otros elementos, proporciona, por ejemplo, un interesante análisis iconográfico e histórico del lugar de origen de la peregrinación de los mexicas según este códice. Un aspecto también destacado, que explica de manera muy clara Castañeda de la Paz, es la preocupación de los pintores por reflejar los años transcurridos desde la salida de Aztlan y de Chicomoztoc, así como del paso por Teopulco y desde la fundación de Tenochtitlan, mediante banderas (pantli, en náhuatl) de diferentes colores. Por último, queremos destacar que Castañeda de la Paz sitúa la versión recogida de la peregrinación dentro de las diversas tradiciones que se han identificado de este relato por la historiografía en las fuentes.

El capítulo cuarto, referido a los anales coloniales, está escrito de manera conjunta por los dos autores que firman la obra y sigue en general el planteamiento del anterior. Es decir, se realiza un comentario general de las láminas, explicando brevemente los acontecimientos reseñados en cada uno de los años que recoge el Mexicanus hasta 1590, aunque en los últimos solo se recogió el signo del año sin información. Esto último 
concuerda con el hecho de que, según los autores del estudio, se dejó de escribir el códice en 1588, por lo que únicamente se había preparado la última lámina de anales que finalizaba en 1590.

El quinto capítulo sirve para tratar tres aspectos generales referidos al manuscrito en general como son el fechamiento, las fases de composición y la autoría del Códice Mexicanus. Si bien podría parecer extraña su ubicación hacia el final del estudio, como señala Oudijk al inicio del texto, su colocación no es casual ya que se abordan estos asuntos apoyándose en lo analizado sobre el contenido del códice en los capítulos previos. Gracias a ello, sus propuestas en cuanto a la fecha en que se comenzó a confeccionar y los diversos momentos en que se registró contenido en el Mexicanus son sólidas y novedosas respecto a lo planteado desde Mengin (1952).

El breve capítulo sexto, escrito como el anterior por Oudijk, se ocupa de la sección que se corresponde con dos pasajes del libro de San Lucas pintados en la lámina 88, relativos a la Tentación de Cristo y la Adoración. Finalmente, este tomo relativo al estudio se cierra con una conclusión que sirve para retomar sus temas principales y constituye una buena recapitulación donde se refuerzan algunas de las principales aportaciones de Castañeda de la Paz y Oudijk para el conocimiento de este documento.

Sobre la base de todo ello, podemos considerar que esta obra constituye una importante aportación tanto para el conocimiento de los códices mesoamericanos como para el de la historia mexica-tenochca y de las primeras décadas del Virreinato de la Nueva España, pasando por diversos aspectos relativos a la cultura prehispánica y colonial del Valle de México.

\section{BIBLIOGRAFÍA}

DIEL Lori B.

2018 The Codex Mexicanus. A Guide to Life in Late Sixteenth-Century New Spain, University of Texas Press, Austin.

\section{CAST AÑEDA DE LA PAZ María}

2013 Conflictos y alianzas en tiempos de cambio: Azcapotzalco, Tlacopan, Tenochtitlan y Tlatelolco (siglos XII-XVI), Instituto de Investigaciones Antropológicas/Universidad Nacional Autónoma de México, México.

\section{CASTAÑEDA DE LA PAZ María}

2017 Verdades y mentiras en torno a don Diego de Mendoza Austria Moctezuma, Instituto de Investigaciones Antropológicas/Universidad Nacional Autónoma de México, El Colegio Mexiquense, Universidad Intercultural del Estado de Hidalgo, México.

\section{MENGIN Ernest}

1952 "Commentaire du Codex mexicanus $n^{0 s} 22-23$ de la Bibliothèque nationale de Paris", Journal de la Société des américanistes, 41 (2), p. 387-498. 
NOTAS

1. La versión digital es accesible en el portal Gallica de la BNF.

\section{AUTORES}

MIGUEL ÁNGEL RUZ BARRIO

Universidad Complutense de Madrid 